\title{
Environmentally Friendly and Efficient Hornet Nest Envelope-Based Photothermal Absorbers
}

\author{
Lijia Xie, Xiaojie Liu, Andrew Caratenuto, Yanpei Tian, Fangqi Chen, Joseph A. DeGiorgis, \\ Yinsheng Wan, and Yi Zheng*
}

Cite This: ACS Omega 2021, 6, 34555-34562

Read Online

\section{ACCESS \\ Џlll Metrics \& More \\ Article Recommendations \\ Supporting Information}

ABSTRACT: Water shortage is a critical global issue that threatens human health, environmental sustainability, and the preservation of Earth's climate. Desalination from seawater and sewage is a promising avenue for alleviating this stress. In this work, we use the hornet nest envelope material to fabricate a biomass-based photothermal absorber as part of a desalination isolation system. This system realizes an evaporation rate of $3.98 \mathrm{~kg} \mathrm{~m}^{-2} \mathrm{~h}^{-1}$ under one-sun illumination, with prolonged evaporation rates all above $4 \mathrm{~kg} \mathrm{~m}^{-2} \mathrm{~h}^{-1}$. This system demonstrates a strong performance of $3.86 \mathrm{~kg} \mathrm{~m}^{-2} \mathrm{~h}^{-1}$ in $3.5 \mathrm{wt} \%$ saltwater, illustrating its effectiveness in evaporation seawater. Thus, with its excellent evaporation rate, great salt rejection ability, and easy fabrication approach, the hornet nest envelope constitutes a promising natural material for solar water treatment applications.

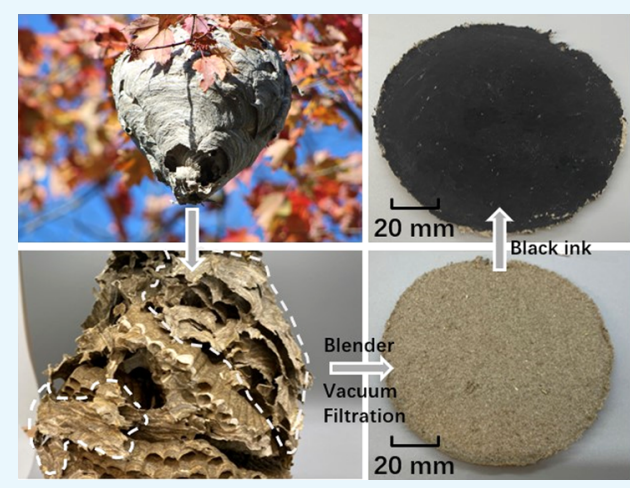

\section{INTRODUCTION}

Presently, water scarcity is a critical global issue that threatens human health, as well as the environment and climate of the Earth. ${ }^{1,2}$ To alleviate this situation, desalination offers a promising and environmentally friendly solution. Desalination processes can be classified into membrane processes, such as reverse osmosis, ${ }^{3}$ and thermal processes, such as solar-driven evaporation. ${ }^{4}$ Compared to other methods, solar-driven evaporation is more attractive because it utilizes clean energy sources and presents minimal environmental impacts. ${ }^{5}$ Solardriven evaporation systems can be categorized into volumetric systems, ${ }^{6-8}$ interfacial systems, ${ }^{9-11}$ isolation systems, ${ }^{12,13}$ and contactless systems ${ }^{14-17}$ based on the location of the photothermal material. Volumetric systems experience significant heat loss because the absorber is directly placed into the fluid, allowing sunlight to heat up the entire water reservoir. In contrast, interfacial systems reduce these energy losses by localizing the heat on the surface of the water. Similarly, isolation systems make additional efforts to reduce heat loss by further minimizing the contact area. ${ }^{18}$ To solve the sustainable problem because of salt accumulation, the contactless systems with infrared photons have been developed during recent years. ${ }^{15}$

As an essential part of a solar-driven evaporation system, many kinds of photothermal materials have been demonstrated, such as metals, semiconductors, carbon-based materials, and biomasses. ${ }^{18}$ Metallic materials that usually offer strong spectral absorption are introduced into the system with different morphologies and compositions to improve their performance, including titanium nitride nanoparticles, ${ }^{19}$ employing chips rather than plates, ${ }^{20}$ naturally inspired morphologies, ${ }^{21}$ and metal-organic frameworks. ${ }^{22,23}$ Semiconductors for solar evaporation, such as $\mathrm{CuFeSe}_{2}$ nanoparticles, ${ }^{24} \mathrm{Au}-\mathrm{CuS}$ gyroid-structured materials, ${ }^{25}$ and copper sulfides, ${ }^{26}$ are also promising absorber materials that present lower cost and good durability. ${ }^{18}$ Compared to the aforementioned materials, carbon nanotubes, ${ }^{27}$ graphite, ${ }^{28,29}$ and other carbon-based materials have the merits of low cost and excellent light absorption over the broad spectrum of solar irradiance. ${ }^{18}$ Biomass also represents a suitable material for vapor generation and is quickly gaining popularity. These natural materials, such as coconut, ${ }^{30}$ cellulose acetate, ${ }^{31}$ kapok, $^{32}$ wood, ${ }^{33}$ rice straw, ${ }^{34}$ bamboo, ${ }^{35}$ and magnolia fruit, $^{36}$ usually have an inherently porous structure, are lightweight, promote simple and low-cost fabrication, and are environmentally friendly. Some of them have a good heat recovery ability. All of these features contribute to the largescale production of solar desalination components.

Here, we use the hornet nest envelope, a biomaterial, within an isolation system for vapor generation. Hornet nests are usually used to investigate the behavior of colonies of wasps $^{37,38}$ and include structural components such as honeycombs and various envelope layers (Figure 1a). In the studies

Received: September 2, 2021

Accepted: November 26, 2021

Published: December 7, 2021 

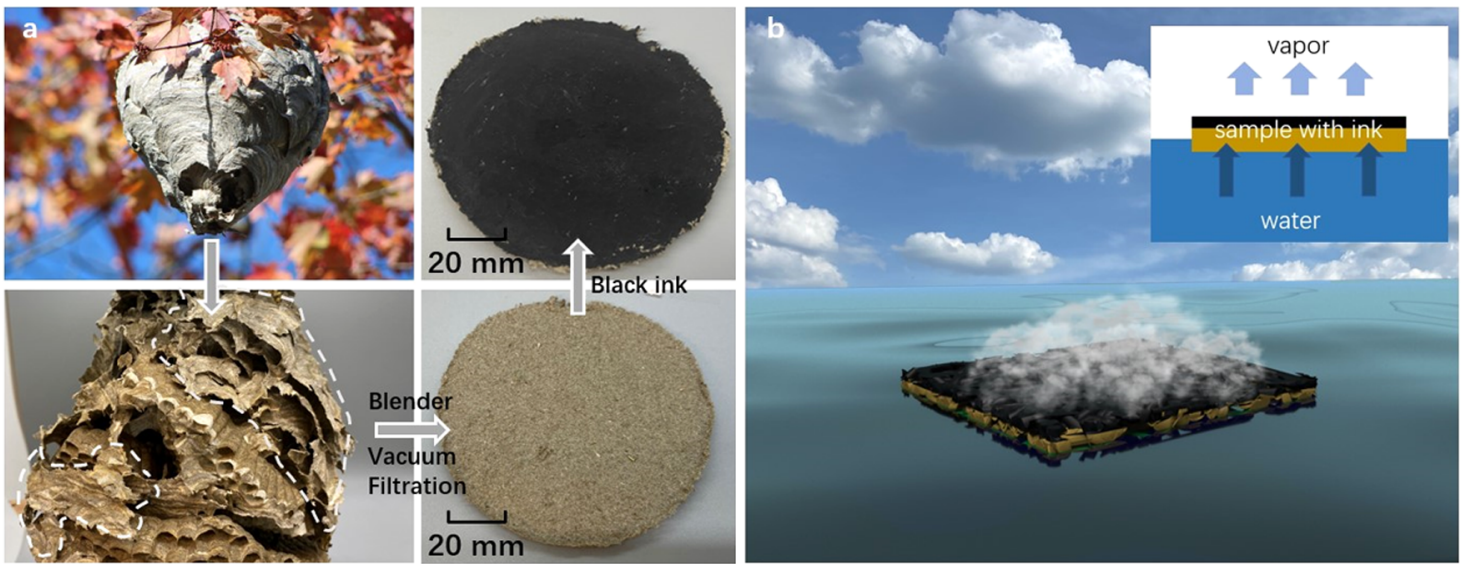

Figure 1. Fabrication process and schematic illustration of the hornet nest envelope evaporator. (a) The fabrication process of the natural photothermal absorber. Envelopes are detached from the hornet nest. Blender and vacuum filtration are utilized to produce thin-layer samples. Then, the top surface is painted with black ink by a cotton sliver. The white dashed area illustrates the hornet nest envelope. (b) Graphical illustration of a biomass hornet nest envelope-based photothermal absorber acting as a solar desalination device. The inset is the illustration of the one-dimensional (1D) water supply channel.
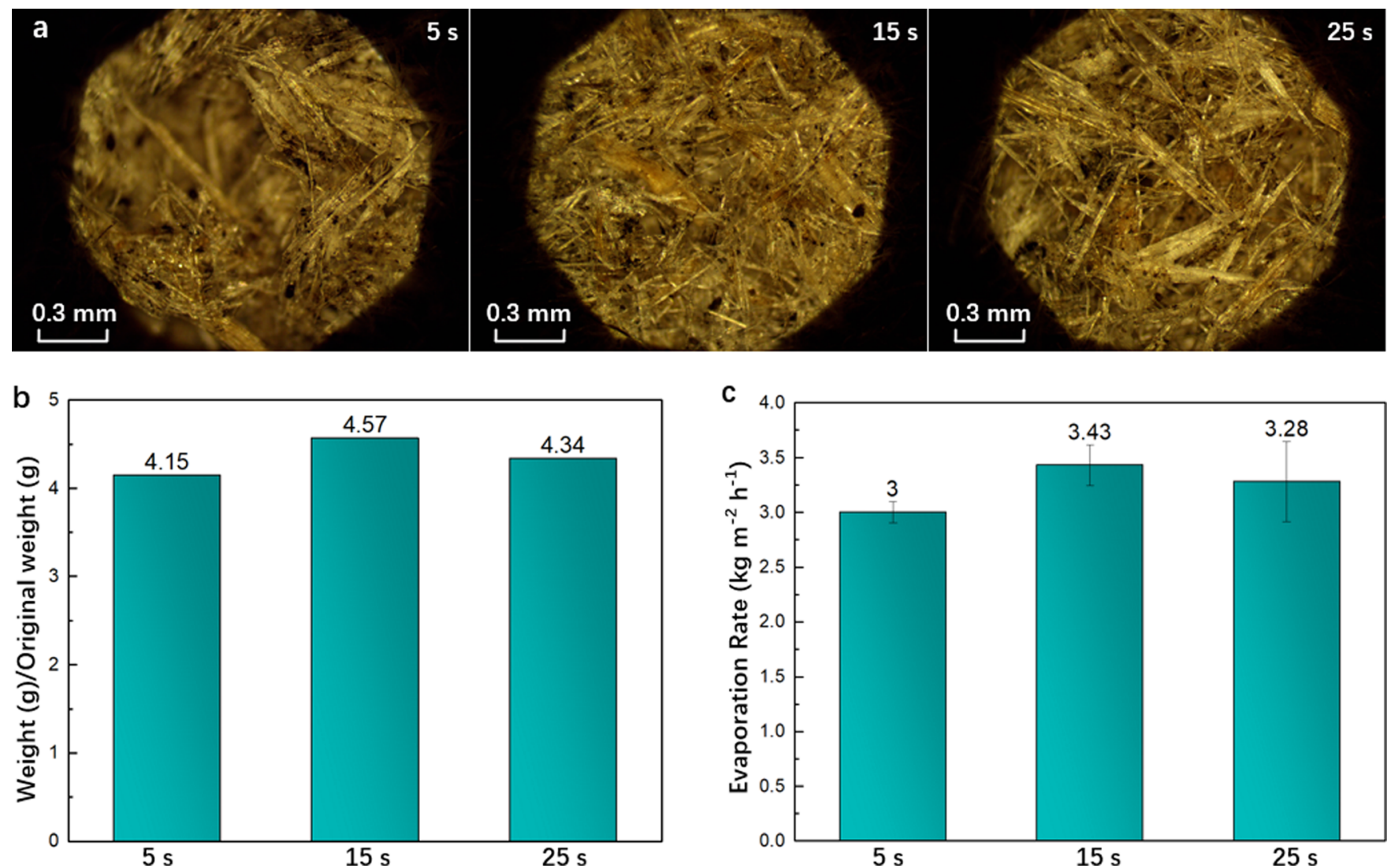

Figure 2. Size effect of hornet nest envelope fibers for water absorption and evaporation capabilities. (a) Microscope images of fibers with varying blending durations. (b) Water absorption test result. (c) Evaporation rate results under an illumination of one sun.

by $\mathrm{Xu}$ et al. $^{39}$ and Dai et al., ${ }^{40}$ honeycomb paper inspired by comb structure is utilized for humidification-dehumidification desalination systems, which could produce more freshwater by recovering condensation heat and forcing airflow. However, in contrast with the unique structure of the honeycomb, the envelope is typically removed and treated as a waste material. Even so, the envelope boasts an excellent porous structure and is lightweight. The envelope is composed of woody fiber $(70 \%)$ and other local materials with saliva $(30 \%) .{ }^{38}$ These properties make it a strong material candidate for a desalination system solar absorber. This work reports a simple fabrication process of a porous solar absorber based on a hornet nest envelope and black ink. Envelope samples with different blending durations and thicknesses have been investigated to establish the most ideal fabrication process. Our system achieves an evaporation rate of $3.98 \mathrm{~kg} \mathrm{~m}^{-2} \mathrm{~h}^{-1}$ under one sun with good stability and salt rejection ability. 

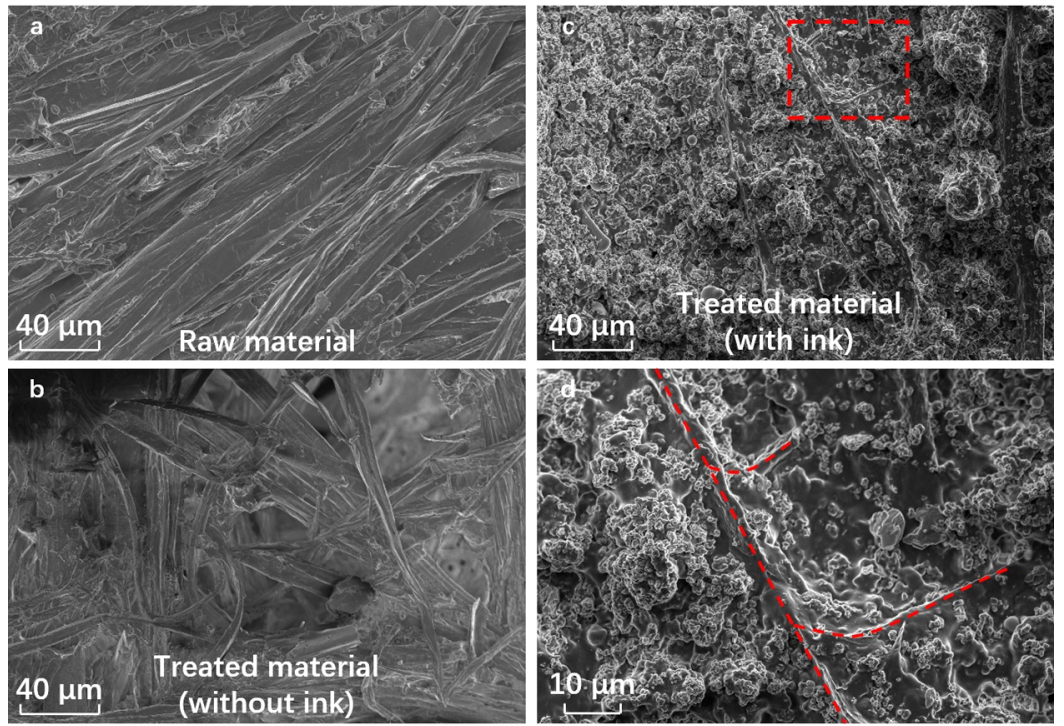

Figure 3. SEM images of samples blended for $15 \mathrm{~s}$ at different fabrication stages. The treated material is blended and filtered. (a) Raw materials. (b) Treated materials without ink. (c) Treated materials with ink. The red square area is zoomed in as panel (d). The red line in panel (d) represents the fibers, and the particle clusters are ink particles.
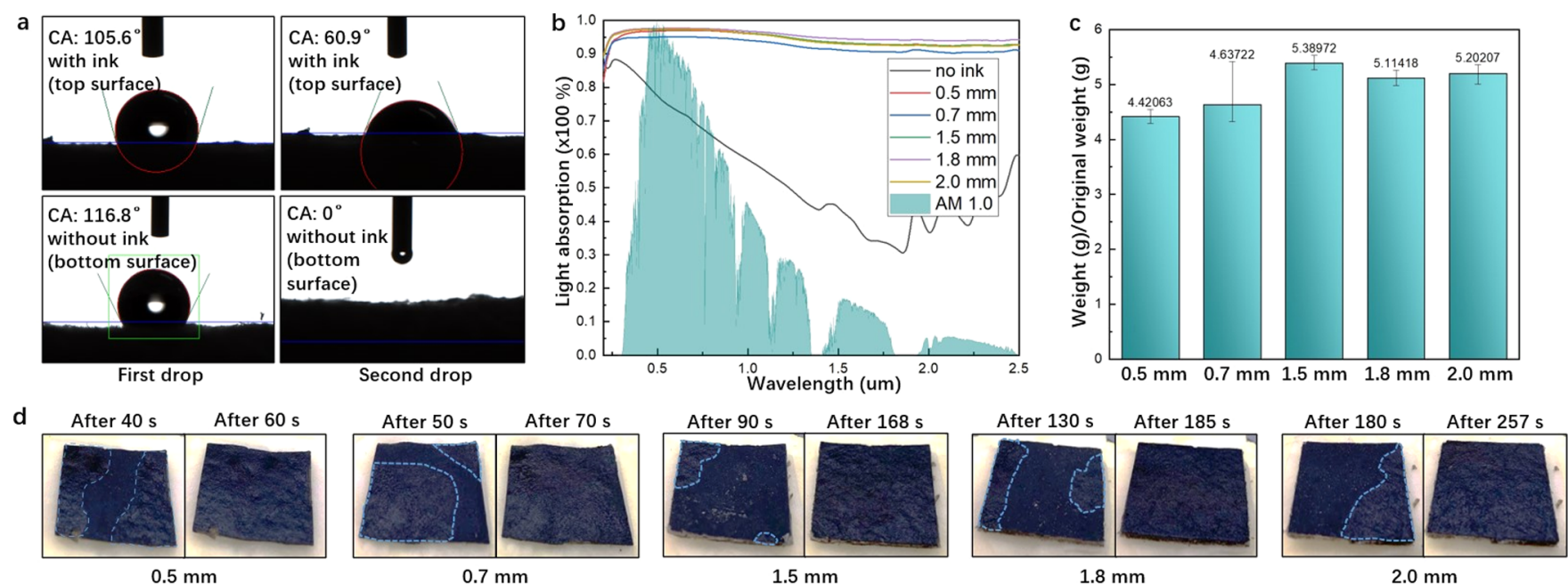

Figure 4. Spectral absorption and hydrophilicity of samples. (a) Contact angle on the surface with and without the ink. A sample of $0.5 \mathrm{~mm}$ thickness is used here. (b) Visible and near-infrared (IR) light absorption spectra of samples with different thicknesses. (c) The ratio of weight changes before and after completely saturated water absorption. (d) Graphic water absorption test results. The bottom side (without ink) of dry samples is placed on the cotton cloth, which serves as a water pathway. When the whole surface is soaked, the time for full saturation is determined.

\section{RESULTS AND DISCUSSION}

2.1. Different Blending Durations. To improve evaporation performance, optimization of the fiber size and fiber distribution is essential for the photothermal absorber, which were affected by the blending duration. Therefore, we use different blending durations of 5,15 , and $25 \mathrm{~s}$ to determine which one would get the higher evaporation performance and called them samples 1, 2, and 3, respectively. Figure 2 illustrates the properties and evaporation rate (ER) with different blending durations. As shown in Figure 2a, the average fiber size is calculated by measuring six different fiber sizes. The average fiber sizes are $0.108,0.059$, and $0.060 \mathrm{~mm}$ of samples 1, 2, and 3, respectively. From this result, it is evident that the fibers are not well dispersed and leave large holes in sample 1, while the fibers in samples 2 and 3 are completely separated. For photothermal materials, the pore size is an important factor for water absorption and salt accumulation. ${ }^{41}$
High porosity samples own high water flux and shortened water path, so they have an excellent water absorption ability and lower salt accumulation. Moreover, in the study by Li et al., ${ }^{42}$ suitable porosity would slightly increase the evaporation rate because of the increase in the water supply. Subsequently, water absorption and solar evaporation tests are employed to determine the most favorable blending duration. Fully absorbing water is defined as the water is visible to the naked eye and saturated the entire top surface. The weight of samples before and after fully absorbing water is measured and shown in Figure 2b. From the result, all samples have excellent water absorption capability as photothermal absorbers. Additionally, Figure $2 c$ presents the ER test results of samples with different blending durations under one sun. From these results, it is illustrated that the 15 and $25 \mathrm{~s}$ samples offer strong hydrophilicity and high evaporation rates. However, the sample with the $15 \mathrm{~s}$ blending duration produces better results 
a
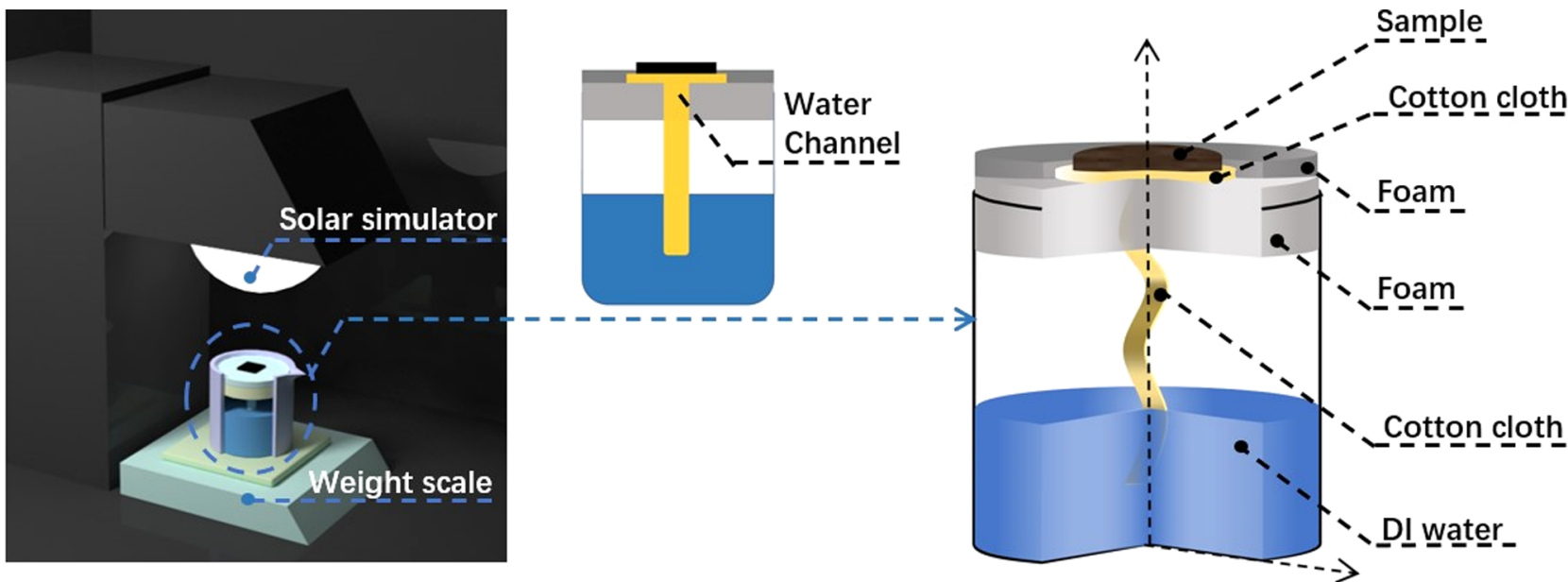

b
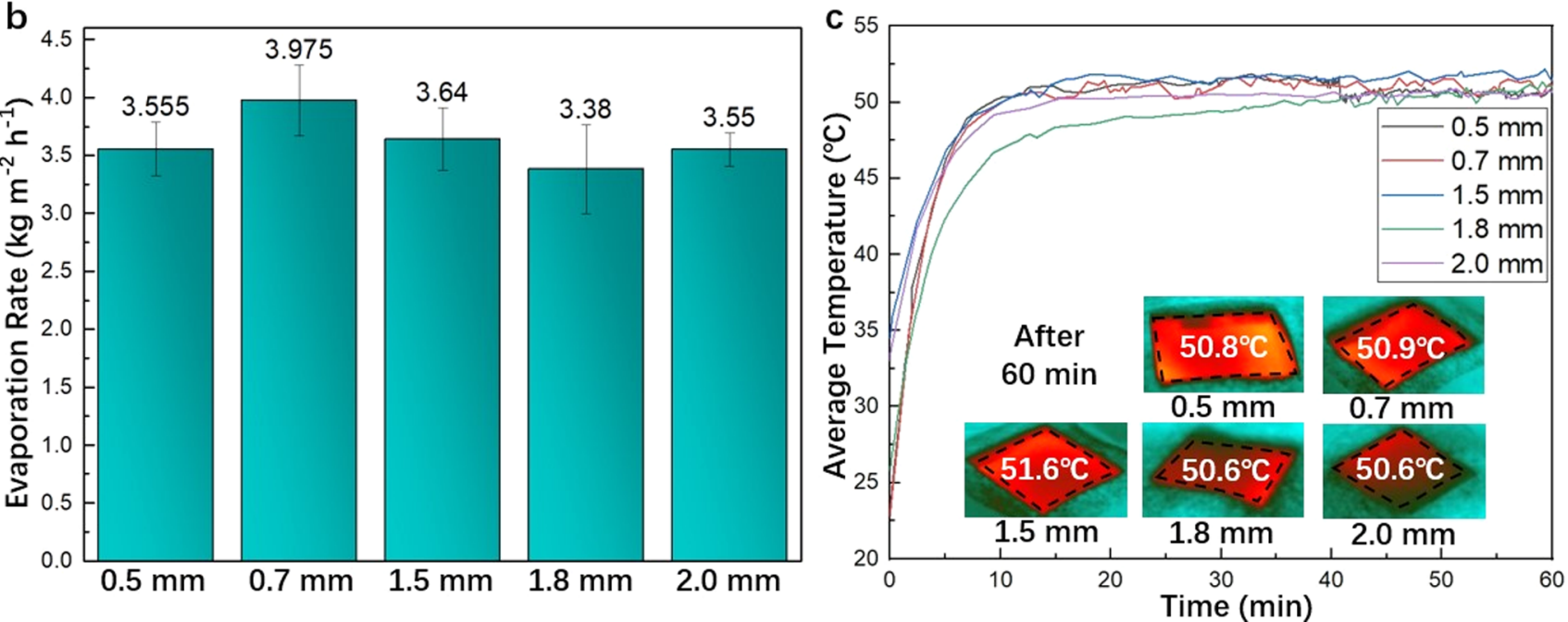

Figure 5. Solar water treatment system and evaporation rate results. (a) Diagram of the solar desalination system setup and 1D water supply channel of the system. Samples are placed on the cotton cloth, and the area without samples are covered by polystyrene foam. Cotton cloth serves as a water pathway. Polyvinyl chloride foam is used for heat insulation and then placed into a container with water. Samples are set on a weight scale, which is connected to a computer for real-time data recording under the solar simulator. (b) Evaporation rate results for samples with different thicknesses. (c) The top surface temperature of various samples and their corresponding thermal camera images after 60 min.

compared to the $25 \mathrm{~s}$ sample for both tests. Therefore, samples of different thicknesses are all fabricated using the $15 \mathrm{~s}$ blending duration, as discussed below.

2.2. Effect of Thickness on Performance. Scanning electron microscopy (SEM) images of samples at different fabrication stages are shown in Figure 3. Compared to the raw material, the treated material without ink has smaller and disorder fibers but still maintains its porous structure. After adding the ink, a relatively smooth surface can be obtained. From Figure 3d, ink particles are evenly distributed on the sample surface.

The contact angle is tested to find out whether the ink would block water transfer (Figure 4a). The time interval between drops is $15 \mathrm{~s}$. A small water drop was dripped on the surface and the contact angle was measured. Then, the unabsorbed water was cleaned before the next water droplet was dripped. As a result, the bottom surface absorbs the second water drop immediately, and the top surface absorbs the third water drop immediately. This result indicates that the black ink has almost no effect on the water transfer. A stability test is operated to check the stability of ink on the sample (Figure $\mathrm{S} 1)$. As a result, the ink layer is very stable and will not block the water transfer.
The thickness of the sample is another crucial factor that affects its evaporation performance. After determining the ideal blending duration and removing the possibility of ink blocking the water channel, sample thickness is evaluated. Samples with thicknesses of $0.5,0.7,1.5,1.8$, and $2.0 \mathrm{~mm}$ are prepared. One $0.5 \mathrm{~mm}$ sample without ink is also prepared for the light absorption test. Figure $4 \mathrm{~b}$ presents the light absorption spectra of samples with different thicknesses. Compared to the samples without ink $(0.5 \mathrm{~mm})$, the inked samples have a better overall spectrum absorption, around 94\%, and it reaches $97 \%$ in the visible light region $(0.4-0.78 \mu \mathrm{m})$. This result shows that light absorption capability is greatly improved by the black ink on the surface, which makes samples excellent candidates for photothermal absorbers. Figure $4 \mathrm{c}, \mathrm{d}$ shows the water absorptance test results. It becomes evident that samples can be fully saturated with water quickly, and thicker samples require more time to be fully saturated. The ink layer would block part of water channels. It is painted manually, so the ink layer on different samples is not completely identical. Therefore, the $1.8 \mathrm{~mm}$ sample has a lower result due to the thicker ink layer.

The ER system setup and evaporation performance are shown in Figure 5. Figure 5a provides the diagram of the ER 

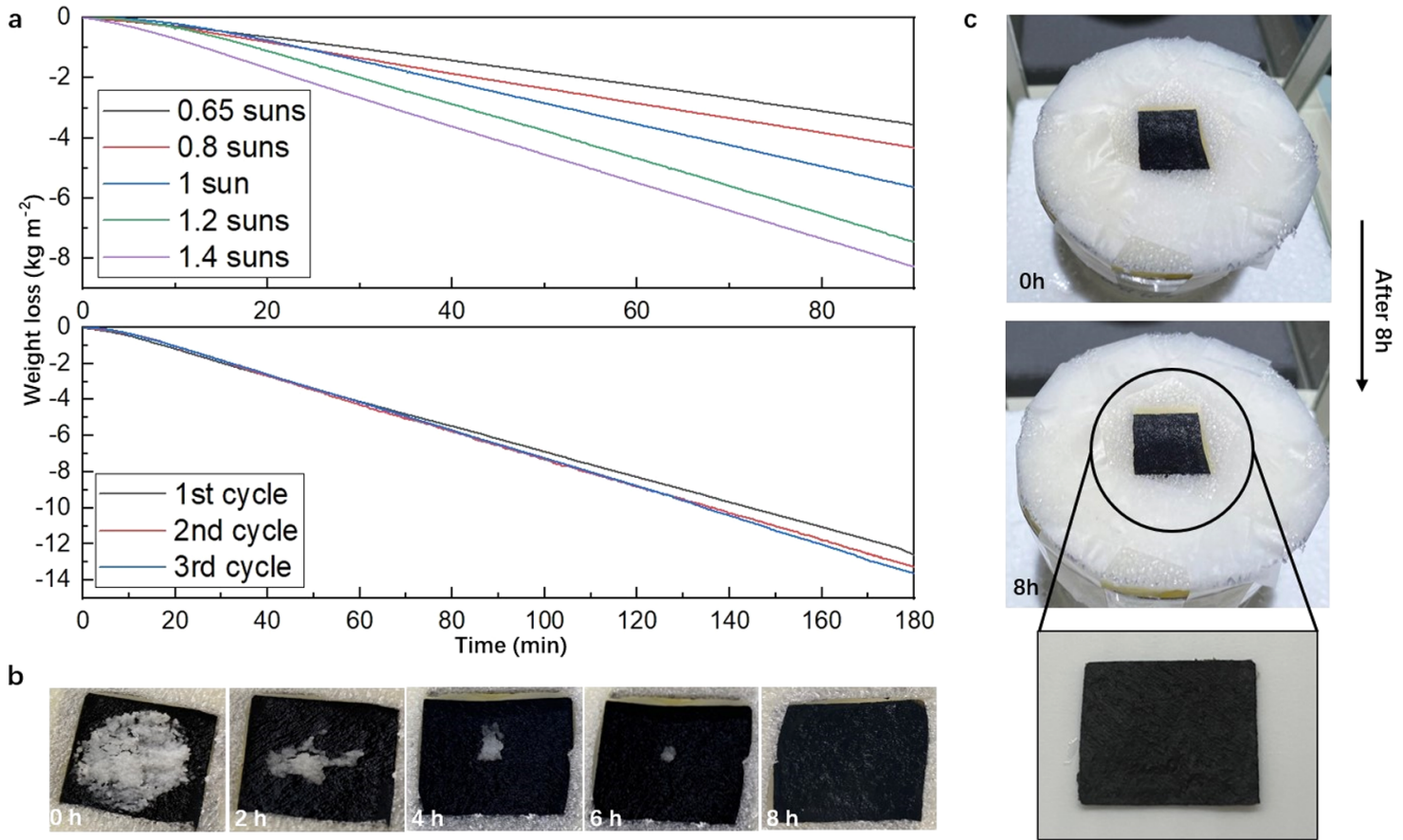

Figure 6. Mass change with varying solar intensities, long-term evaporation test, and salt rejection abilities of the sample. (a) A mass change of 0.7 $\mathrm{mm}$ sample under different sun intensities and different cycles, using a period of $3 \mathrm{~h}$ for one cycle. (b) Salt self-cleaning test with $0.25 \mathrm{~g}$ of salt on the surface for a period of $8 \mathrm{~h}$ without illumination. (c) Salt accumulation test with $3.5 \mathrm{wt} \%$ saltwater under 1 sun for $8 \mathrm{~h}$.

system. Samples are placed on the cotton cloth, which serves as a water pathway, and the area without samples is covered by polyvinyl chloride foam, which is used for heat insulation. Then, samples are set on a weight scale under the solar simulator. The weight scale was connected to a computer, which could monitor and record the mass change of the water. The ER results with deionized (DI) water under one sun and corresponding surface temperature monitor results are shown in Figure 5b,c. All samples demonstrate efficient evaporation rates above $3.50 \mathrm{~kg} \mathrm{~m}^{-2} \mathrm{~h}^{-1}$. Among them, the $0.7 \mathrm{~mm}$ sample has the best performance of $3.98 \mathrm{~kg} \mathrm{~m}^{-2} \mathrm{~h}^{-1}$. Samples thinner and thicker than $0.7 \mathrm{~mm}$ cause a decrease in the ER. For thinner samples, they cannot store enough water for water vapor transition. While for thicker samples, the water needs more time to pass through the sample and heat loss is higher because of the long distance for heat transformation. This result presents that a $0.7 \mathrm{~mm}$ thickness balances the water and heat transformation and a $0.7 \mathrm{~mm}$ thickness sample becomes the best choice for high evaporation performance. Besides, the thickness of the sample has almost no effect on the surface temperature during the ER test, as shown in Figure 5c. The average surface temperature becomes stable around $50{ }^{\circ} \mathrm{C}$ after $10 \mathrm{~min}$ in all cases to achieve a stable evaporation process. Besides, a thermal conductivity of the $0.7 \mathrm{~mm}$ sample is 0.056 $\mathrm{W} \mathrm{m} \mathrm{m}^{-1} \mathrm{~K}^{-1}$. The thermal conductivity of natural fibers usually varies from 0.039 to $0.053 \mathrm{~W} \mathrm{~m}^{-1} \mathrm{~K}^{-1}$. ${ }^{43}$ Thermal camera images of samples with different thicknesses after $60 \mathrm{~min}$ of solar exposure are shown in the inset of Figure 5c. Subsequently, the DI water is replaced with a solution of 3.5 wt \% saltwater to simulate seawater. The resulting ER result is $3.86 \mathrm{~kg} \mathrm{~m}^{-2} \mathrm{~h}^{-1}$ (Figure S2), showing that the sample operates efficiently even for saline solutions.

The photothermal efficiency and solar-to-vapor efficiency are calculated. The detailed calculation is shown in the Supporting Information Note S3. ${ }^{44,45}$ The corresponding photothermal efficiency of the $0.7 \mathrm{~mm}$ sample is calculated to be $69.95 \%$, and the corresponding solar-to-vapor efficiency of the $0.7 \mathrm{~mm}$ sample is calculated to be $241.94 \%$.

2.3. Long-Time Test and Salt Rejection Ability. Based on the results above, the $0.7 \mathrm{~mm}$ sample with a $15 \mathrm{~s}$ blending duration is used for long-term ER tests, varying solar intensity ER tests, and salt rejection tests (Figure 6). In a practical scenario, the solar intensity will change over the course of a day, so it is important to verify the ER performance under different solar intensities in DI water (Figure 6a). The ER of the samples decreases as the sun intensity decreases. The ER results under $0.65,0.8,1,1.2$, and 1.4 suns are $2.49,3.01,3.98$, 5.47 , and $5.70 \mathrm{~kg} \mathrm{~m}^{-2} \mathrm{~h}^{-1}$, respectively. This shows that the sample can operate efficiently under a large variety of solar irradiation conditions, making it a versatile component for a solar desalination system. The surface temperature also becomes stable after $10 \mathrm{~min}$, which means the evaporation process becomes stable after $10 \mathrm{~min}$ (Figure S3). Figure 6a also shows the long-term mass change. We define one cycle as one $3 \mathrm{~h}$ test and evaluate the performance for three cycles. Afterward, the average ER for each cycle is calculated. The results are $4.15 \mathrm{~kg} \mathrm{~m}^{-2} \mathrm{~h}^{-1}$ for the first cycle, $4.42 \mathrm{~kg} \mathrm{~m}^{-2} \mathrm{~h}^{-1}$ for the second cycle, and $4.54 \mathrm{~kg} \mathrm{~m}^{-2} \mathrm{~h}^{-1}$ for the third cycle (Figure $\mathrm{S} 4$ ). Figure $6 \mathrm{~b}$ provides the salt rejection test results. A $0.7 \mathrm{~mm}$ thick, $15 \mathrm{~s}$ blended sample is used for the desalination test. The system setup is the same as the ER test except that there is no solar input, and the DI water is replaced by $3.5 \mathrm{wt}$ $\%$ saltwater. Then, $0.25 \mathrm{~g}$ salt is put on the surface of the sample. After $8 \mathrm{~h}$, salt is fully dissolved into saltwater via the sample. This result shows that it has great salt rejection ability, which is an important factor for the desalination system at night. 


\section{CONCLUSIONS}

In summary, a hornet nest envelope, a cheap and environmentally friendly biomass, is used to fabricate a solar absorber for use within an isolation desalination system. The fabrication process is straightforward, cost-effective, and requires very few devices. An evaporation rate of $3.98 \mathrm{~kg} \mathrm{~m}^{-2} \mathrm{~h}^{-1}$ is achieved under one sun, while an average rate of $4.36 \mathrm{~kg} \mathrm{~m}^{-2} \mathrm{~h}^{-1}$ is reached for long-term tests. The evaporation rate in saltwater is also desirable, which is $3.86 \mathrm{~kg} \mathrm{~m}^{-2} \mathrm{~h}^{-1}$ under one sun. Besides, it also shows good salt rejection ability. Future work can focus on different morphologies and surface treatments of the envelope.

\section{EXPERIMENTAL SECTION}

4.1. Materials and Fabrication. The fabrication process is shown in Figure 1a. First, the envelope was detached from the hornet nest, which was provided by Lincoln Woods State Park, Lincoln, RI. One gram of the envelope and $300 \mathrm{~mL}$ of water are placed into a high-speed blender (Vitamix E310). The envelope material was blended for varying durations $(5,15$, and $25 \mathrm{~s}$ ). Vacuum filtration was used to extract the envelope fiber from the blended solution of the envelope fiber and water. Finally, after the treated material was air-dried, the black ink (Black 3.0 paint) was painted on its top surface to improve its photothermal-absorbing ability. Approximately $1 \mathrm{~g}$ of envelope yields a sample with a thickness of $0.7 \mathrm{~mm}$. This thickness can be modified using different amounts of envelope raw materials. Cotton cloth, which serves as water pathways, was supplied by Webril. Poly(vinyl chloride) foam, which is used for heat insulation, was purchased from the McMaster-Carr; $0.25 \mathrm{~g}$ of sea salt (Morton) was prepared for the salt rejection test. The details of the preparation process are shown in Figure S6.

4.2. Characterization. SEM images were characterized by scanning electron microscopy (SEM, S5200, Hitachi Company) under an acceleration voltage of $10 \mathrm{kV}$. The surface morphology of the samples with various blending durations was observed using a trinocular metallurgical microscope (ME300TZA-3M) with a 50× lens. The water contact angle of the samples was measured by a contact angle goniometer (DSA-25, Krüss, Germany) with a $5 \mu \mathrm{L}$ DI water droplet at room temperature according to the sessile droplet method. The light absorption $(0.2-2.5 \mu \mathrm{m})$ was measured by a Jasco V770 spectrophotometer at an incident angle of $6^{\circ}$ with the ISN-923 $60 \mathrm{~mm}$ BaSO4-based integrating sphere. The incident angle is set by the company to avoid inaccurate data when testing mirror surfaces. The thermal conductivity was measured by the isotropic standard module of TPS $2500 \mathrm{~s}$. Solar evaporation and desalination test were operated by a solar simulator (Newport, 94081a). Infrared images of samples were taken by an FLIR A655C thermal camera.

\section{ASSOCIATED CONTENT}

\section{SI Supporting Information}

The Supporting Information is available free of charge at https://pubs.acs.org/doi/10.1021/acsomega.1c04851.

Details of photothermal efficiency calculation; ink layer stability test; evaporation rate with 3.5 wt \% saltwater; and the surface temperature change under different sun intensities (PDF)

\section{AUTHOR INFORMATION}

\section{Corresponding Author}

Yi Zheng - Department of Mechanical and Industrial Engineering, Northeastern University, Boston, Massachusetts 02115, United States; ำ orcid.org/0000-0003-4963-9684; Email: y.zheng@northeastern.edu

\section{Authors}

Lijia Xie - Department of Mechanical and Industrial Engineering, Northeastern University, Boston, Massachusetts 02115, United States

Xiaojie Liu - Department of Mechanical and Industrial Engineering, Northeastern University, Boston, Massachusetts 02115, United States

Andrew Caratenuto - Department of Mechanical and Industrial Engineering, Northeastern University, Boston, Massachusetts 02115, United States

Yanpei Tian - Department of Mechanical and Industrial Engineering, Northeastern University, Boston, Massachusetts 02115, United States; (1) orcid.org/0000-0003-4181-9517

Fangqi Chen - Department of Mechanical and Industrial Engineering, Northeastern University, Boston, Massachusetts 02115, United States

Joseph A. DeGiorgis - Department of Biology, Providence College, Providence, Rhode Island 02918, United States; Whitman Center, Marine Biological Laboratory, Woods Hole, Massachusetts 02543, United States

Yinsheng Wan - Department of Biology, Providence College, Providence, Rhode Island 02918, United States

Complete contact information is available at:

https://pubs.acs.org/10.1021/acsomega.1c04851

\section{Author Contributions}

L.X.: methodology, data curation, formal analysis, investigation, validation, and writing-original draft; X.L. and A.C.: methodology and writing-review and editing; Y.T.: resources and writing-review and editing; F.C. and J.A.D.: investigation and writing-review and editing; Y.W.: conceptualization and data discussion; and Y.Z.: conceptualization, supervision, and writing-review and editing.

\section{Notes}

The authors declare no competing financial interest.

\section{ACKNOWLEDGMENTS}

The authors acknowledge the support from the National Science Foundation, USA, through grant number CBET1941743 and the National Science Foundation under EPSCoR Cooperation Agreement OIA-1655221. The authors thank Robert Tammaro, Rhode Island Department of Environmental Management, Parks and Recreation, and Louie Kerr of the Central Microscopy Facility, Marine Biological Laboratory, for his assistance with SEM sample preparation and microscopy.

\section{REFERENCES}

(1) Pakmehr, S.; Yazdanpanah, M.; Baradaran, M. How collective efficacy makes a difference in responses to water shortage due to climate change in southwest Iran. Land Use Policy 2020, 99, No. 104798.

(2) World Wildlife Fund. Water Scarcity. https://www.worldwildlife. org/threats/water-scarcity (Retrieved May 15, 2021).

(3) Yao, Y.; Zhang, P.; Jiang, C.; DuChanois, R. M.; Zhang, X.; Elimelech, M. High performance polyester reverse osmosis desalina- 
tion membrane with chlorine resistance. Nat. Sustainability 2021, 4, $138-146$.

(4) Okampo, E. J.; Nwulu, N. Optimisation of renewable energy powered reverse osmosis desalination systems: A state-of-the-art review. Renewable Sustainable Energy Rev. 2021, 140, No. 110712.

(5) Xu, Z.; Li, Z.; Jiang, Y.; Xu, G.; Zhu, M.; Law, W.-C.; Yong, K.T.; Wang, Y.; Yang, C.; Dong, B.; Xing, F. Recent advances in solardriven evaporation systems. J. Mater. Chem. A 2020, 8, 25571-25600.

(6) Duan, H.; Chen, R.; Zheng, Y.; Xu, C. Photothermal properties of plasmonic nanoshell-blended nanofluid for direct solar thermal absorption. Opt. Express 2018, 26, 29956.

(7) Rabbi, H. M. F.; Sahin, A. Z. Performance improvement of solar still by using hybrid nanofluids. J. Therm. Anal. Calorim. 2021, 143, $1345-1360$

(8) Iqbal, A.; Mahmoud, M. S.; Sayed, E. T.; Elsaid, K.; Abdelkareem, M. A.; Alawadhi, H.; Olabi, A. G. Evaluation of the nanofluid-assisted desalination through solar stills in the last decade. J. Environ. Manage. 2021, 277, No. 111415.

(9) Fang, Q.; Li, T.; Chen, Z.; Lin, H.; Wang, P.; Liu, F. Full Biomass-Derived Solar Stills for Robust and Stable Evaporation To Collect Clean Water from Various Water-Bearing Media. ACS Appl. Mater. Interfaces 2019, 11, 10672-10679.

(10) Liu, C.; Hong, K.; Sun, X.; Natan, A.; Luan, P.; Yang, Y.; Zhu, $\mathrm{H}$. An 'antifouling' porous loofah sponge with internal microchannels as solar absorbers and water pumpers for thermal desalination. J. Mater. Chem. A 2020, 8, 12323-12333.

(11) Xu, Y.; Xiao, X.; Fan, X.; Yang, Y.; Song, C.; Fan, Y.; Liu, Y. Low cost, facile, environmentally friendly all biomass-based squid inkstarch hydrogel for efficient solar-steam generation. J. Mater. Chem. A 2020, 8, 24108-24116.

(12) Chen, Y.; Sha, C.; Wang, W.; Yang, F. Solar-driven steam generation on nitrogen-doped graphene in a $2 \mathrm{D}$ water path isolation system. Mater. Res. Express 2020, 7, No. 015507.

(13) Liu, Z.; Song, H.; Ji, D.; Li, C.; Cheney, A.; Liu, Y.; Zhang, N.; Zeng, X.; Chen, B.; Gao, J.; et al. Extremely Cost-Effective and Efficient Solar Vapor Generation under Nonconcentrated Illumination Using Thermally Isolated Black Paper. Global Challenges 2017, 1, No. 1600003.

(14) Menon, A. K.; Haechler, I.; Kaur, S.; Lubner, S.; Prasher, R. S. Enhanced solar evaporation using a photo-thermal umbrella for wastewater management. Nat. Sustainability 2020, 3, 144-151.

(15) Bian, Y.; Tang, K.; Tian, L.; Zhao, L.; Zhu, S.; Lu, H.; Yang, Y.; Ye, J.; Gu, S. Sustainable solar evaporation while salt accumulation. ACS Appl. Mater. Interfaces 2021, 13, 4935-4942.

(16) Bian, Y.; Tian, Y.; Tang, K.; Li, W.; Zhao, L.; Yang, Y.; Ye, J.; $\mathrm{Gu}, \mathrm{S}$. Sustainable solar evaporation from solute surface via energy downconversion. Global Challenges 2021, 5, No. 2000077.

(17) Cooper, T. A.; Zandavi, S. H.; Ni, G. W.; Tsurimaki, Y.; Huang, Y.; Boriskina, S. V.; Chen, G. Contactless steam generation and superheating under one Sun illumination. Nat. Commun. 2018, 9, No. 5086.

(18) Gao, M.; Zhu, L.; Peh, C. K.; Ho, G. W. Solar absorber material and system designs for photothermal water vaporization towards clean water and energy production. Energy Environ. Sci. 2019, 12, 841-864. (19) Bian, Y.; Tang, K.; Xu, Z.; Ma, J.; Shen, Y.; Hao, L.; Chen, X.; Nie, K.; Li, J.; Ma, T.; et al. Highly efficient solar steam generation by hybrid plasmonic structured tin/mesoporous anodized alumina membrane. J. Mater. Res. 2018, 33, 3857-3869.

(20) Sharshir, S. W.; Peng, G.; Elsheikh, A. H.; Eltawil, M. A.; Elkadeem, M. R.; Dai, H.; Zang, J.; Yang, N. Influence of basin metals and novel wick-metal chips pad on the thermal performance of solar desalination process. J. Cleaner Prod. 2020, 248, No. 119224.

(21) Zheng, Z.; Li, H.; Zhang, X.; Jiang, H.; Geng, X.; Li, S.; Tu, H.; Cheng, X.; Yang, P.; Wan, Y. High-absorption solar steam device comprising Au@Bi2MoO6-CDs: Extraordinary desalination and electricity generation. Nano Energy 2020, 68, No. 104298.

(22) Kadhom, M.; Deng, B. Metal-organic frameworks (MOFs) in water filtration membranes for desalination and other applications. Appl. Mater. Today 2018, 11, 219-230.
(23) Ou, R.; Zhang, H.; Truong, V. X.; Zhang, L.; Hegab, H. M.; Han, L.; Hou, J.; Zhang, X.; Deletic, A.; Jiang, L.; Simon, G. P.; Wang, H. A sunlight-responsive metal-organic framework system for sustainable water desalination. Nat. Sustainability 2020, 3, 10521058.

(24) Liu, H.; Chen, C.; Wen, H.; Guo, R.; Williams, N. A.; Wang, B.; Chen, F.; Hu, L. Narrow bandgap semiconductor decorated wood membrane for high-efficiency solar-assisted water purification. $J$. Mater. Chem. A 2018, 6, 18839-18846.

(25) Sun, P.; Wang, W.; Zhang, W.; Zhang, S.; Gu, J.; Yang, L.; Pantelić, D.; Jelenković, B.; Zhang, D. 3D Interconnected Gyroid $\mathrm{Au}-\mathrm{CuS}$ Materials for Efficient Solar Steam Generation. ACS Appl. Mater. Interfaces 2020, 12, 34837-34847.

(26) Guo, Z.; Ming, X.; Wang, G.; Hou, B.; Liu, X.; Mei, T.; Li, J.; Wang, J.; Wang, X. Super-hydrophilic copper sulfide films as light absorbers for efficient solar steam generation under one sun illumination. Semicond. Sci. Technol. 2018, 33, No. 025008.

(27) Corry, B. Designing Carbon Nanotube Membranes for Efficient Water Desalination. J. Phys. Chem. B 2008, 112, 1427-1434.

(28) Kashyap, V.; Al-Bayati, A.; Sajadi, S. M.; Irajizad, P.; Wang, S. H.; Ghasemi, H. A flexible anti-clogging graphite film for scalable solar desalination by heat localization. J. Mater. Chem. A 2017, 5, 15227-15234.

(29) Liu, Y.; Tian, J.; Xu, L.; Wang, Y.; Fei, X.; Li, Y. Multilayer graphite nano-sheet composite hydrogel for solar desalination systems with floatability and recyclability. New J. Chem. 2020, 44, 2018120191.

(30) Ovando-Medina, V. M.; Escobar-Villanueva, A. G.; MartínezGutiérrez, H.; González-Ortega, O. Interfacial photothermal water evaporator based on nanoporous microwave-expanded graphite and coconut waste fibers@recycled polystyrene as substrate. Int. J. Energy Res. 2020, 44, 10878-10893.

(31) Angel, N.; Vijayaraghavan, S. N.; Yan, F.; Kong, L. Electrospun Cadmium Selenide Nanoparticles-Loaded Cellulose Acetate Fibers for Solar Thermal Application. Nanomaterials 2020, 10, 1329.

(32) Mu, P.; Bai, W.; Fan, Y.; Zhang, Z.; Sun, H.; Zhu, Z.; Liang, W.; $\mathrm{Li}, \mathrm{A}$. Conductive hollow kapok fiber-PPy monolithic aerogels with excellent mechanical robustness for efficient solar steam generation. $J$. Mater. Chem. A 2019, 7, 9673-9679.

(33) Li, T.; Liu, H.; Zhao, X.; Chen, G.; Dai, J.; Pastel, G.; Jia, C.; Chen, C.; Hitz, E.; Siddhartha, D.; Yang, R.; Hu, L. Scalable and Highly Efficient Mesoporous Wood-Based Solar Steam Generation Device: Localized Heat, Rapid Water Transport. Adv. Funct. Mater. 2018, 28, No. 1707134.

(34) Storer, D. P.; Phelps, J. L.; Wu, X.; Owens, G.; Khan, N. I.; Xu, H. Graphene and Rice-Straw-Fiber-Based 3D Photothermal Aerogels for Highly Efficient Solar Evaporation. ACS Appl. Mater. Interfaces 2020, 12, 15279-15287.

(35) Bian, Y.; Du, Q.; Tang, K.; Shen, Y.; Hao, L.; Zhou, D.; Wang, $\mathrm{X}$; $\mathrm{Xu}, \mathrm{Z}$.; Zhang, H.; Zhao, L.; et al. Carbonized bamboos as excellent 3D solar vapor-generation devices. Adv. Mater. Technol. 2019, 4, No. 1800593.

(36) Bian, Y.; Shen, Y.; Tang, K.; Du, Q.; Hao, L.; Liu, D.; Hao, J.; Zhou, D.; Wang, X.; Zhang, H.; et al. Carbonized tree-like furry magnolia fruit-based evaporator replicating the feat of plant transpiration. Global Challenges 2019, 3, No. 1900040.

(37) Yamane, S.; Makino, S. Bionomics of Vespa analis insularis and V. mandarinia latilineata in Hokkaido, northern Japan, with notes on vespine embryo nests (Hymenoptera: Vespidae). Insecta Matsumurana $1977,12,1-33$.

(38) Ertürk, Ö. Determination of some structural features of the nest paper materials of Dolichovespula Saxonica Fabricius, 1793 (Hymenoptera: Vespinae) in Turkey. Entomol. Res. 2017, 47, 286294.

(39) Xu, H.; Zhao, Y.; Dai, Y. J. Experimental study on a solar assisted heat pump desalination unit with internal heat recovery based on humidification-dehumidification process. Desalination 2019, 452, $247-257$. 
(40) Dai, Y. J.; Wang, R. Z.; Zhang, H. F. Parametric analysis to improve the performance of a solar desalination unit with humidification and dehumidification. Desalination 2002, 142, 107118.

(41) Huang, Q.; Du, C.; Guo, C.; Huang, C.; Wang, X. A highefficiency salt-rejecting solar evaporator with optimized porous structure for continuous solar desalination. Appl. Therm. Eng. 2021, 187, No. 116515.

(42) Li, Y.; Hong, W.; Li, H.; Yan, Z.; Wang, S.; Liu, X.; Li, B.; Jiang, H.; Niu, X. Solar absorber with tunable porosity to control the water supply velocity to accelerate water evaporation. Desalination 2021, 511, No. 115113

(43) Stapulionienè, R.; Vaitkus, S.; Vèjelis, S.; Sankauskaitè, A. Investigation of Thermal Conductivity of Natural Fibres Processed by Different Mechanical Methods. Int. J. Precis. Eng. Manuf. 2016, 17, 1371-1381.

(44) Zhou, J.; Gu, Y.; Liu, P.; Wang, P.; Miao, L.; Liu, J.; Wei, A.; $\mathrm{Mu}, \mathrm{X}$.; Li, J.; Zhu, J. Development and evolution of the system structure for highly efficient Solar steam generation from zero to three dimensions. Adv. Funct. Mater. 2019, 29, No. 1903255.

(45) Zhu, M.; Li, Y.; Chen, F.; Zhu, X.; Dai, J.; Li, Y.; Yang, Z.; Yan, X.; Song, J.; Wang, Y.; Hitz, E.; Luo, W.; Lu, M.; Yang, B.; Hu, L. Plasmonic wood FOR high-efficiency Solar steam generation. Adv. Energy Mater. 2018, 8, No. 1701028. 